\title{
Hydroxylation of a Hederagenin Derived Saponin by a Xylareaceous Fungus Found in Fruits of Sapindus saponaria
}

\author{
Michael Murgu, ${ }^{a}$ Luiz F. Arruda Santos, ${ }^{a}$ Gezimar D. de Souza, ${ }^{a}$ Cristina Daolio, ${ }^{a}$ Bernd Schneider, ${ }^{b}$ \\ Antônio Gilberto Ferreira ${ }^{a}$ and Edson Rodrigues-Filho*,a
}

\author{
${ }^{a}$ Departamento de Química, Universidade Federal de São Carlos, CP 676, 13565-905 São Carlos-SP, Brazil \\ ${ }^{b}$ Max Planck Institute for Chemical Ecology, Beutenberg Campus, Hans-Knöll-Straße 8, D-07745 Jena, Germany
}

\begin{abstract}
Durante nossos estudos visando a obtenção de microorganismos endofíticos associados a plantas tropicais, um fungo do grupo Xylareaceae foi isolado das partes internas dos frutos de Sapindus saponaria. Os frutos de $S$. saponaria acumulam grande quantidade de saponinas triterpênicas e sesquiterpênicas. A saponina 3-O-( $\beta$-D-xilopiranosil)-( $1 \rightarrow 3)-\alpha$-L-ramnopiranosil- $(1 \rightarrow 2)-\alpha-\mathrm{L}-$ arabinopiranosil-hederagenina foi isolada por métodos cromatográfios após saponificação do extrato bruto obtido dos frutos de $S$. saponaria e admistrada junto ao meio de cultivo usado para crescimento do fungo. Após extração dos metabólitos obtidos, uma nova saponina foi purificada por CLAE em escala preparativa e caracterizada como um derivado $22 \alpha$-hidroxilado. Essa saponina hidroxilada teve sua estrutura molecular elucidada através da interpretação de dados de EM/EM e RMN.
\end{abstract}

During our screening of tropical plants for endophyte microorganisms, a Xylareaceous fungus was found living on the internal part of Sapindus saponaria fruits. The fruits of S. saponaria accumulate great amounts of triterpenoidal and sesquiterpenoidal saponins. The saponin 3-O-( $\beta$ D-xylopyranosyl)-( $1 \rightarrow 3)-\alpha$-L-rhamnopyranosyl-( $(1 \rightarrow 2)-\alpha$-L-arabinopyranosyl-hederagenin was isolated using chromatographic methods, after alkaline hydrolysis of the crude extract obtained from $S$. saponaria fruits and added to the culture medium used to grows the fungus. A new saponin was isolated from this experiment by preparative scale HPLC and characterized as a $22 \alpha$-hydroxy derivative. The structure of this hydroxylated saponin was elucidated based on interpretation of MS/MS data and NMR spectra.

Keywords: Sapindus saponaria, saponin, Xylaria, biotransformation, hydroxylation

\section{Introduction}

As part of our investigations on the chemical aspects of tropical plants and microorganisms interactions, we have been studying the plant Sapindus saponaria (Sapindaceae). Following many other Sapindaceas, S. saponaria produces annually great amounts of small fruits where a sap is accumulated. ${ }^{1}$ Studying the glycoside composition of this soap by means of mass spectrometry coupled with liquid chromatography (LC-MS), it was found that those fruits accumulate on their pericarp huge amounts of monodesmosidic triterpene (SAPs) and bisdesmosidic sesquiterpene (acyclic sesquiterpene oligoglycosides, ASOGs) acetylated saponins. ${ }^{2}$ Saponins are usually referred

*e-mail: edson@dq.ufscar.br as antifungal and antibacterial compounds, being the monodesmosidic the most active ones. ${ }^{3,4}$ These compounds form a group of chemical weapons used by plants in the fight against fungi, and the protection against pathogenic microbes is probably their natural role in plants. ${ }^{4-6}$ Despite this status of saponins as antimicrobial compounds, during our chemical studies on $S$. saponaria fruits it was observed that a fungus grows from a hairy structure attached to the seeds. The seeds are in contact with the pericarps where saponins are accumulated. In our previous studies this fungus was isolated and tentatively classified as a member of Xylareaceae, based on morphological characteristics and secondary metabolite profile, and we have also reported that this fungus is able to metabolize the glycosides present in S. saponaria fruits. ${ }^{7}$ Thus, using LC-MS it was shown that the ASOGs are completely consumed by this Xylareaceous 
fungus, while the SAPs and some exogenous glycosides are hydroxylated at the aglicon part of the molecule, in a small scale fermentation experiment. In the present work, the saponin 1 (Figure 1) was purified from a saponificated extract obtained from fruits of $S$. saponaria and used for a scaled up biotransformation reaction. We describe here this biotransformation experiment and a complete structural characterization of the hydroxylated saponin produced by the fungus.
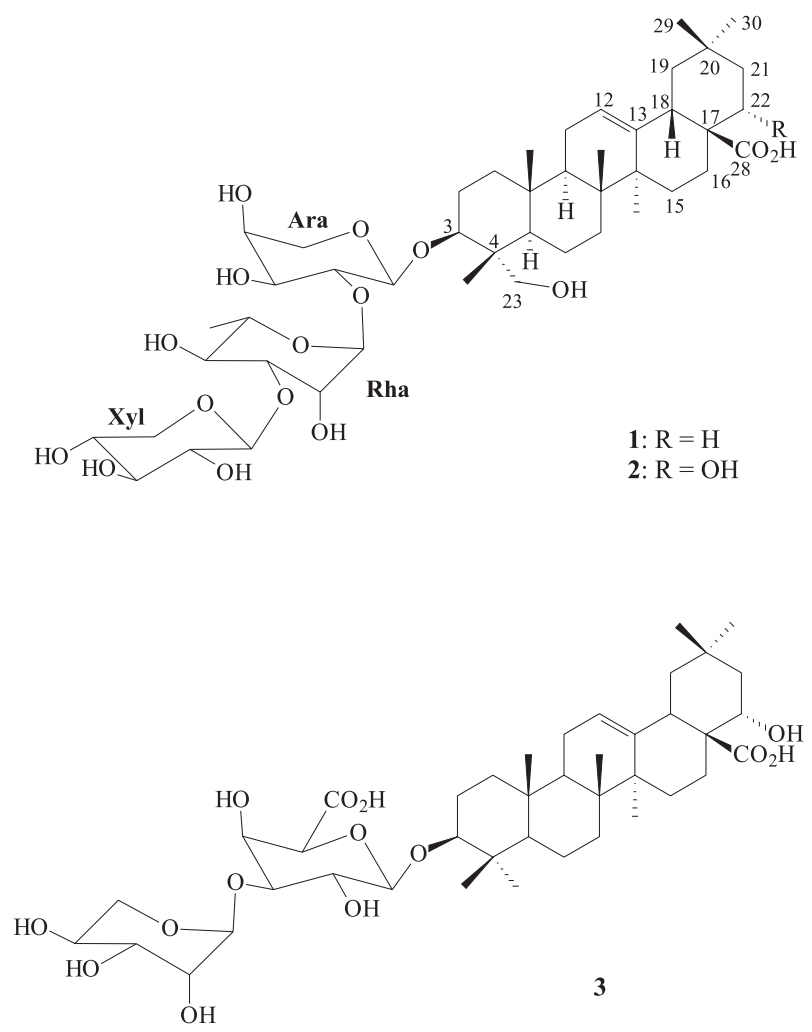

Figure 1. Molecular structure of the saponin starting material (1), the hydroxylated product (2), and a model compound (3).

\section{Results and Discussion}

In a previous work, we have shown that the saponins produced by $S$. saponaria occur as a complex mixture of naturally non-regiosselective acetylated glycosides. ${ }^{2}$ Alkaline hydrolysis of these natural glycosides produced simplified mixtures of compounds formed of only four SAPs and five ASOGs. Preparative scale HPLC separation of the SAP fraction let to isolation of pure saponin $\mathbf{1}$, which was characterized as 3-O-( $\beta$-D-xylopyranosyl)- $(1 \rightarrow 3)$ $\alpha$-L-rhamnopyranosyl- $(1 \rightarrow 2)$ - $\alpha$-L-arabinopyranosylhederagenin by comparison of both MS and NMR spectra with those published by Grover and co-workers. ${ }^{8}$

Saponin $1(100 \mathrm{mg})$ was submitted to biotransformation experiment and, after the conclusion of this experiment, it was isolated $18 \mathrm{mg}$ (18\% yield) of the hydroxylated compound 2 . The MS data indicated that $\mathbf{2}$ was produced by the addition of an oxygen atom in $\mathbf{1}$. The ESI mass spectrum of 1 shows a deprotonated molecule at $\mathrm{m} / z 881\left([\mathrm{M}-\mathrm{H}]^{-}\right)$ in agreement with the molecular formula $\mathrm{C}_{46} \mathrm{H}_{74} \mathrm{O}_{16}$ (882 Da) of SAP 1. Analyses of the compound produced by the fungus revealed a compound with a peak at $\mathrm{m} / \mathrm{z} 897$ $\left([\mathrm{M}-\mathrm{H}]^{-}\right)$in its mass spectrum, probably associated with a compound whose molecular weight is $898 \mathrm{Da}$. The product ion spectrum obtained from $\mathrm{m} / \mathrm{z} 881$ (from $\mathbf{1}$ ) shows ions detected at $m / z 749$ ([SAP-xyl] $\left.]^{-}\right), 603$ ([SAP-xyl-ara]') and 471 ([SAP-xyl-ara-gly $]^{-}=$[Aglycone $^{-}$) which correspond to the losses of the sugar chain from the saponin. The same fragmentation experiment, using the precursor ion of $m / z, 897\left([\mathrm{M}-\mathrm{H}]^{-}\right)$generated from $\mathbf{2}$, produced exactly the same type of fragmentation but with the peaks in the mass spectrum shifted by $16 \mathrm{Da}$. For example, the peak at $m / z 765$ corresponds to the fragmentation that produced $\mathrm{m} / \mathrm{z}, 749$ from 1, plus $16 \mathrm{Da} ; \mathrm{m} / \mathrm{z} 747$ corresponds to loss of water (18 Da) from $m / z 765$. Therefore the presence of $m / z, 487$ ([Aglycon] $]^{-}$) in the product ion spectrum of $\mathrm{m} / \mathrm{z} 897$ is an indicative that the addition of the 16 mass unit (oxygen) have occurred at the aglycon of the saponin $\mathbf{1}$ moiety.

The $1 \mathrm{D}{ }^{1} \mathrm{H}$ NMR spectra of saponins $\mathbf{1}$ and $\mathbf{2}$ are very complex and contains numerous overlapping signals. Thus, direct comparison of the 1D spectra did not allow visualization of an extra hydrogen atom bounded to an oxygen bearing carbon in 2 . On the other hand, the 2D NMR spectra $\left({ }^{1} \mathrm{H}-{ }^{1} \mathrm{H}\right.$ COSY $)$ were efficient to localize this hydrogen signal. Figure 2 shows a comparison of a sector from the COSY spectra obtained for $\mathbf{1}$ and $\mathbf{2}$. The partial spectrum of $\mathbf{1}$ (Figure 2A) shows correlations of hydrogen H-12 $(\delta$ 5.49) with H-11 $(\delta$ 1.92) and of the H-3 $(\delta$ 4.29) with H-2 $(\delta$ 2.01). These correlations are also seen in compound 2 spectrum (Figure 2B) which shows an extra contour due H-22 ( $\delta$ 4.55) / H-21 ( $\delta 1.81)$ coupling. In the HSQC spectrum of 2 , the hydrogen at $\delta 4.55$ (H-22) is correlated with the ${ }^{13} \mathrm{C}$ NMR signal at $\delta 70.9$ (C-22), corroborating the MS data and confirming the hydroxylation at the aglicone in saponin $\mathbf{1}$.

The position where the oxygen atom was added in the saponin 1 was suggested by interpretation of NMR spectral data analyzed in comparison with the saponin starting material and model compounds found in the literature. The ${ }^{1} \mathrm{H}$ NMR spectrum of $\mathbf{2}$ shows five signals for methyl groups $(\delta 1.34,3 \mathrm{H}-27 ; \delta 1.15,3 \mathrm{H}-24 ; \delta 1.09,3 \mathrm{H}-30$; $\delta 1.09,3 \mathrm{H}-26 ; \delta 1.00,3 \mathrm{H}-25 ; \delta 0.98,3 \mathrm{H}-29)$ like found in spectrum of $\mathbf{1}$.

The 2D ${ }^{1} \mathrm{H}-{ }^{1} \mathrm{H}$ TOCSY spectrum of $\mathbf{2}$ showed three continuous spin systems for rings $\mathrm{A}$ ( $\mathrm{H}-1$ to $\mathrm{H}-3), \mathrm{B}$ (H-5 to H-7) and $\mathrm{C}$ (H-9 to H-12). These correlations are 

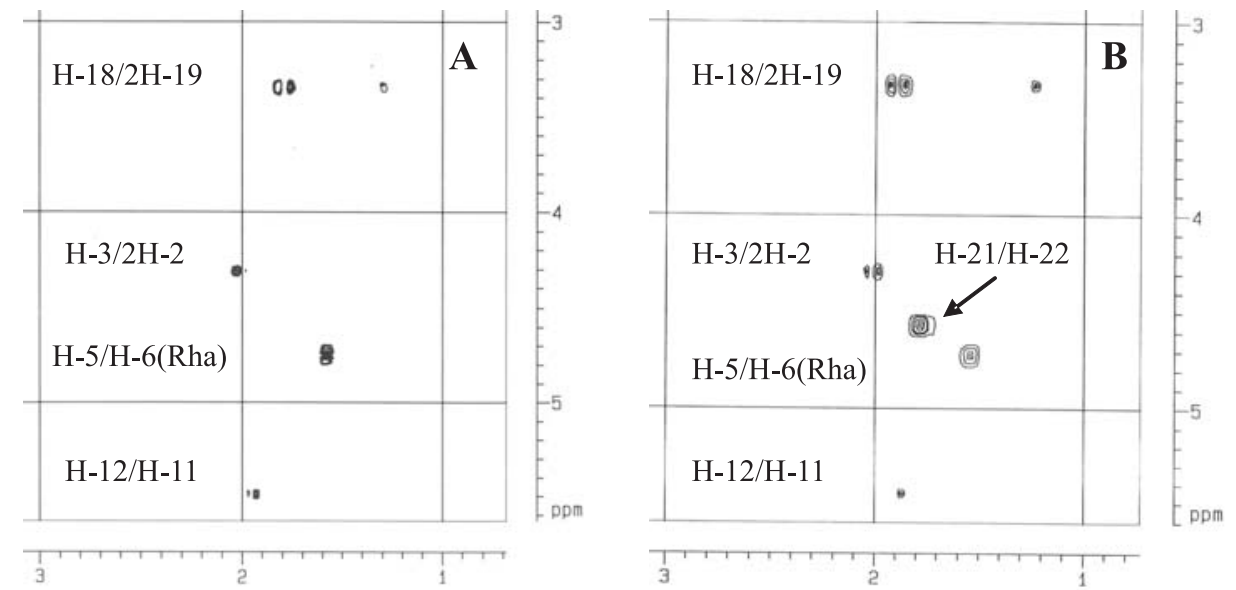

Figure 2. Sections of the ${ }^{1} \mathrm{H}-{ }^{1} \mathrm{H}$ COSY spectra of $\mathbf{1}$ (A) compared to $\mathbf{2}$ (B) showing an additional correlation due H-22 $(\delta 4.55)$ coupled with $\mathrm{H}-21$ $(\delta 1.81)$.

Table 1. ${ }^{13} \mathrm{C}$ NMR data ${ }^{\mathrm{a}}$ of aglicons in saponins $\mathbf{1}$ and $\mathbf{2}$ and calculated ${ }^{13} \mathrm{C}$ chemical shift difference indicating the positioning of the additional $\mathrm{OH}$ group in $\mathbf{2}$ and comparison with a model compound (3)

\begin{tabular}{|c|c|c|c|c|c|}
\hline $\mathrm{C}$ & 1 & 2 & $\Delta \delta^{1 \mathrm{~b}}$ & $3^{11}$ & $\Delta \delta^{2 \mathrm{c}}$ \\
\hline 1 & 39.3 & 38.8 & -0.5 & 38.4 & -0.4 \\
\hline 2 & 26.5 & 26.6 & +0.1 & 26.4 & -0.2 \\
\hline 3 & 81.3 & 80.9 & -0.4 & 89.1 & +8.2 \\
\hline 4 & 43.8 & 43.1 & -0.7 & 39.4 & -3.7 \\
\hline 5 & 47.9 & 47.9 & 0.0 & 55.5 & +7.6 \\
\hline 6 & 18.4 & 17.9 & -0.4 & 18.3 & +0.4 \\
\hline 7 & 33.2 & 33.2 & 0.0 & 32.9 & -0.3 \\
\hline 8 & 40.0 & 39.8 & +0.2 & 39.8 & 0.0 \\
\hline 9 & 48.5 & 47.4 & -1.1 & 47.8 & +0.4 \\
\hline 10 & 37.2 & 36.7 & -0.5 & 36.8 & +0.1 \\
\hline 11 & 24.0 & 23.7 & -0.3 & 23.6 & -0.1 \\
\hline 12 & 122.6 & 122.7 & +0.1 & 122.7 & 0.0 \\
\hline 13 & 145.5 & 144.0 & -1.5 & 144.0 & 0.0 \\
\hline 14 & 42.4 & 42.3 & -1.1 & 42.4 & +0.1 \\
\hline 15 & 28.7 & 27.8 & -0.9 & 27.8 & 0.0 \\
\hline 16 & 24.0 & 16.7 & -7.3 & 16.8 & +0.1 \\
\hline 17 & 46.9 & 53.0 & +6.1 & 53.0 & 0.0 \\
\hline 18 & 42.4 & 43.3 & +0.9 & 43.4 & +0.1 \\
\hline 19 & 47.0 & 45.7 & -1.3 & 45.8 & +0.1 \\
\hline 20 & 31.2 & 31.4 & +0.2 & 31.4 & 0.0 \\
\hline 21 & 34.6 & 43.4 & +8.8 & 43.1 & -0.3 \\
\hline 22 & 33.6 & 70.9 & +37.3 & 71.3 & +0.4 \\
\hline 23 & 64.4 & 63.7 & -0.7 & 27.9 & -35.8 \\
\hline 24 & 14.4 & 14.0 & -0.4 & 16.8 & -2.9 \\
\hline 25 & 16.4 & 15.9 & -0.5 & 15.2 & -0.7 \\
\hline 26 & 17.9 & 17.2 & -0.7 & 17.2 & 0.0 \\
\hline 27 & 26.4 & 26.3 & -0.1 & 26.6 & +0.3 \\
\hline 28 & 182.0 & 179.3 & -2.7 & 179.3 & 0.0 \\
\hline 29 & 33.1 & 32.5 & -0.6 & 33.3 & +0.8 \\
\hline 30 & 23.9 & 25.0 & +1.1 & 25.0 & 0.0 \\
\hline
\end{tabular}

${ }^{\mathrm{a}}$. At $100 \mathrm{MHz}$ in pyridine- $d_{5}{ }^{\mathrm{b}}{ }^{\mathrm{b}} . \Delta \delta^{1}=\delta \mathbf{2}-\delta \mathbf{1}$. $^{\mathrm{c}} . \Delta \delta^{2}=\delta \mathbf{3}-\delta \mathbf{2} . \Delta \delta<0.5$ is considered not significant variation. indicative that the hydroxylation did not occur at rings A, $\mathrm{B}$ and C. Couplings of $2 \mathrm{H}-15$ with $2 \mathrm{H}-16$ were not clearly seen due severe signal overlapping although analysis of HSQC data allows the ascribing of C-15 ( $\delta$ 27.8) and C-16 $\left(\delta\right.$ 16.7) signals. The ${ }^{1} \mathrm{H}$ NMR signal for $\mathrm{H}-18$ $(\delta 3.38$, dd, $J 3.4 / 8.7 \mathrm{~Hz}$ ), showing typical couplings with vicinal methylene hydrogens, exclude the possibility of hydroxylation at C-19. Therefore, by exclusion, the hydroxyl group was added by the fungus at C-21 or C-22. The comparative analysis of the ${ }^{13} \mathrm{C}$ NMR data for $\mathbf{1}$ and $\mathbf{2}$ (Table 1) also shows that the chemical shifts for the carbons at rings $\mathrm{A}, \mathrm{B}$ and $\mathrm{C}$ are very similar. When compared with $\mathbf{1}$, the ${ }^{13} \mathrm{C}$ chemical shift difference $(\Delta \delta)$ becomes important only for some carbons (C-16 to C-22) at rings D and E.

A literature survey covering the recent publications on saponin and triterpene molecular structures revealed three compounds interesting for comparison with 2 . Thus, the ${ }^{13} \mathrm{C}$ NMR spectrum of $\mathbf{2}$ was compared with a 16-hydroxyoleanolic acid derived saponin isolated from Albizia procera, ${ }^{9}$ a triterpene 21 -hydroxyhederagenin, ${ }^{10}$ and finally with scoparianoside (3), a 22-hydroxyolenolic acid derived saponin, isolated from fruits of Kochia scoparia. ${ }^{11}$ The best mach found indicated compound $\mathbf{2}$ to be a 22-hydroxy saponin. The ${ }^{13} \mathrm{C}$ NMR data of $\mathbf{2}$ (Table 1) shows good agreement ( $\Delta \delta$ close to zero) with those of $\mathbf{3}$ considering the signals for carbons at rings D and E. The chemical shift of C-17 ( $\delta 53.0)$ appears to be a good guide for the assignment of the hydroxyl group at $\mathrm{C}-22$, since it is at $c a . \delta 46.0-48.0$ in other rings $\mathrm{D} / \mathrm{E}$ hydroxylated compounds. ${ }^{9-11}$ In the same way observed for scoparianoside $(\mathbf{3})^{11}$, it was not detected H-22/C-28 HBMC long-range correlation. Probably, the long relaxation time of C-28 and the cis $\mathrm{H}-22 / \mathrm{C}-28$ spatial relationship (Figure 3) difficult this observation. The shielding effect $(\Delta \delta=-7.3)$ 


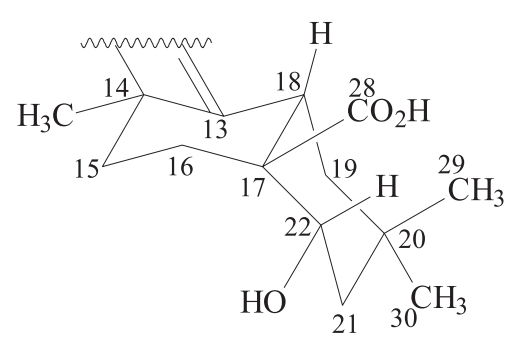

Figure 3. 3D visualization of rings $D$ and $E$ of the hydroxylated saponin 2.

of the C-22-hydroxyl over C-16 $(\delta 16.7)$ and a nOe between $\mathrm{H}-22$ and $3 \mathrm{H}-29$ observed in ROESY spectrum indicates that compound $\mathbf{2}$ is a $22 \alpha$-hydroxylated product of $\mathbf{1}$.

In general, deglycosylations (hydrolysis at the sugar chain) are frequently reported as saponin metabolisms done by microorganisms. ${ }^{12-14}$ Hydroxylation (monooxygenase expression) is the reaction that occurred in saponin $\mathbf{1}$. This biochemistry process may find important technological application since expression of monooxigenase from fungi in saponins is not commonly found in the literature.

\section{Experimental}

\section{Equipment}

Preparative scale HPLC separations were performed using a Shimadzu equipment (LC-8A pump, CBM-10A communication module) equipped with an UV detector (SPD-6AV) set at $206 \mathrm{~nm}$. HPLC grade acetonitrile (ACN) was obtained from Mallinckrodt, and $\mathrm{H}_{2} \mathrm{O}$ was purified in a Milli-Q system (Millipore). ESI-MS/MS spectra were acquired in negative ion mode on a triple quadrupole Micromass Quattro LC spectrometer, equipped with a Z-Spray API ion source and a megaflow electrospray probe. NMR spectra were recorded in $\mathrm{C}_{5} \mathrm{D}_{5} \mathrm{~N}$ (Aldrich) on a Bruker DRX 400 spectrometer operating at $400 \mathrm{MHz}$ for hydrogen and $100 \mathrm{MHz}$. Some analysis were also performed using a Bruker AV 500 Ultrashield spectrometer operating at 500 $\mathrm{MHz}$ for ${ }^{1} \mathrm{H}$ and $125 \mathrm{MHz}$ for ${ }^{13} \mathrm{C}$.

\section{Plant material}

Fruits of S. saponaria were collected in São Carlos, São Paulo State, Brazil. A voucher specimen (No. 003651) was deposited in the herbarium of the Botanic Department of Universidade Federal de São Carlos, Brazil.

\section{Extraction and isolation of SAP 1}

Fruits of $S$. saponaria were dried under circulating air at a temperature of $50{ }^{\circ} \mathrm{C}$ during $48 \mathrm{~h}$. Finely powdered pericarpe $(451.3 \mathrm{~g})$ of dried fruits separated from seeds was extracted with methanol. The methanol extract was concentrated by distillation under reduced pressure and finally lyophilized to eliminate residual water. Part of the lyophilized extract (15.0 of $101.3 \mathrm{~g}$ ) was stirred with $130 \mathrm{~mL}$ of aqueous $\mathrm{NaOH} 2 \mathrm{~mol} \mathrm{~L}^{-1}$ for $30 \mathrm{~min}$. The reaction solutions were acidified with $23 \mathrm{~mL}$ of $\mathrm{HCl} 2 \mathrm{~mol} \mathrm{~L}^{-1}$. The resulting solution was passed through an octadecylsilyl (ODS) open column, which was further eluted with pure $\mathrm{MeOH}$. The $\mathrm{MeOH}$ solution was evaporated and then part of the extract obtained ( $c a .3 \mathrm{~g}$ ) was repetitively subjected to preparative scale reverse phase HPLC ( $c$ a. $150 \mathrm{mg}$ per injection), on an ODS column (Shimadzu Prep K, $2.0 \times 25.0 \mathrm{~m})$, eluted with $\mathrm{ACN}: \mathrm{H}_{2} \mathrm{O}(1: 1 \mathrm{v} / \mathrm{v})$ at a flow rate of $10 \mathrm{~mL} \mathrm{~min} \mathrm{mith}^{-1}$, with UV dection at $206 \mathrm{~nm}$.

3-O-( $\beta$-D-xylopyranosyl)-( $1 \rightarrow 3)$ - $\alpha$-L-rhamnopyranosyl$(1 \rightarrow 2)$ - $\alpha$-L-arabinopyranosyl-hederagenin $(\mathbf{1})$

White amorphous powder; $[\alpha]_{\mathrm{D}}^{25}+113.4^{\circ}(\mathrm{MeOH}, c$ 0.001); ${ }^{1} \mathrm{H}$ NMR (400 MHz, $\mathrm{C}_{5} \mathrm{D}_{5} \mathrm{~N}$ ): Aglicon: $\delta 5.49$ (br s, H-12), 4.29 (m, H-3), 4.28 (d, J 10 Hz, H-23a), 3.93 (d, $J 10 \mathrm{~Hz}, \mathrm{H}-23 \mathrm{~b}$ ), 3.32 (dd, J 3.7/9.0 Hz, H-12), 1.26 (s, 3H-27), 1.14 (s, 3H-24), 1.06 (s, 3H-30), 1.04 (s, 3H-26), 1.01 (s, 3H-25), 0.93 (s, 3H-29), Arabinose: 5.07 (d, J 7 Hz, H-1), 4.62 (m, H-2), 4.00 (dd, J 3.9/8.1 Hz, H-3), 4.14 (m, H-4), 4.30 (m, H-5a), 3.67 (br d, J 10.8 Hz, H-5b), Rhamnose: 6.35 (br s, H-1), 4.92 (m, H-2), 4.83 (dd, J 2.9/9.5 H-3), 4.46 (t, J 9.5 Hz, H-4), 4.85 (dq, J 6.2/9.5 Hz, H-5), 1.55 (d, J 6.2 Hz, 3H-6), Xylose: 5.32 (d, J 7.3 Hz, H-1), 3.94 (t, J 8.8 Hz, H-2), 3.99 (t, J 9.5 Hz, H-3), 4.00 (dt, $J 9.5 / 5.1 \mathrm{~Hz}, \mathrm{H}-4), 4.13$ (dd, $J 11.0 / 5.1 \mathrm{~Hz}, \mathrm{H}-5 \mathrm{a}), 3.56$ (dd, $J$ 11.0/9.5 Hz, H-5b); ${ }^{13} \mathrm{C}$ NMR (100 MHz, $\left.\mathrm{C}_{5} \mathrm{D}_{5} \mathrm{~N}\right)$ : see Table 1; ESIMS (daughter ion scan, $35 \mathrm{eV}$.): 881 [M-H]' (100), 749 [M-H-Xyl]- (23), 603 [M-H-Xyl-Rha] (29), 471 [Hederagenin - H] $]^{-}(16)$.

\section{Isolation of fungus}

Details of fungus isolation procedures and tentative identification are described elsewhere. ${ }^{7}$ After their isolation, the fungus was labeled with the code LaBioMMi217 and deposited at the Laboratory Biochemistry and Micromolecular of Microorganisms - LaBioMMi - of the Chemistry Department of the Federal University of São Carlos, São Carlos, Brazil.

\section{Biotransformation experiments and chemical analysis}

The fungus was seeded in a Petri dish containing PDA (potato-dextrose-agar) and allowed to grow for 12 
days. The saponin 1 (100 mg) was dissolved in $20 \mathrm{~mL}$ of distilled water and equally distributed in twenty 0.5 -liter Erlenmeyer flasks, each containing $150 \mathrm{~mL}$ of liquid medium (45 g glucose, $0.48 \mathrm{~g} \mathrm{NH}_{4} \mathrm{NO}_{3}, 5.0 \mathrm{~g} \mathrm{KH}_{2} \mathrm{PO}_{4}$, $1.0 \mathrm{~g} \mathrm{MgSO}_{4}, 0.1 \mathrm{~g} \mathrm{FeSO}_{4}, 0.015 \mathrm{~g} \mathrm{CuSO}_{4}, 0.161 \mathrm{~g} \mathrm{ZnSO}_{4}$,

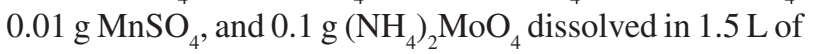
distilled water). These Erlenmeyer flasks were autoclaved $\left(121{ }^{\circ} \mathrm{C}, 25 \mathrm{~min}\right.$ ) and then pieces of the PDA (potatodextrose-agar) culture containing mycelium were added to fifteen of the twenty flasks (five were kept as control) and were allowed at $25^{\circ} \mathrm{C}$ standing in the dark during 15 days. The mycelium was separated by gravity filtration and the liquid phase was concentrated under reduced pressure and finally lyophilized. The extract was repetitively subjected to preparative scale separations using the same conditions described above for the isolation of $\mathbf{1}$. These procedures let to isolation of $18.0 \mathrm{mg}$ of pure saponin 2. The ESI-MS/ MS spectra were acquired in negative ion mode on a triple quadrupole Micromass Quattro LC spectrometer. The desolvation and ion source block temperatures were set, respectively, at 300 and $125^{\circ} \mathrm{C}$. Gaseous $\mathrm{N}_{2}$ was used to nebulize $(80 \mathrm{~L} / \mathrm{H})$ and desolvate $(350 \mathrm{~L} / \mathrm{H})$. The optimal voltages found for the probe and ion source components to produce maximum intensity of the ions $[\mathrm{M}-\mathrm{H}]^{-}$were $3.3 \mathrm{kV}$ for the stainless steel capillary, $38 \mathrm{~V}$ for the sample cone, and $6 \mathrm{~V}$ for the extractor cone. The parent/daughter runs (MS/MS) were performed by adding $\mathrm{Ar}$ in the collision cell to produce a pressure of $1.5 \times 10^{-3} \mathrm{mBar}$ for collisional induced dissociation (CID). The optimal collisional energy used to decompose the ions [M-H]- was $25-30 \mathrm{eV}$.

3-O-( $\beta$-D-xylopyranosyl)-( $1 \rightarrow 3)$ - $\alpha$-L-rhamnopyranosyl$(1 \rightarrow 2)$ - $\alpha$-L-arabinopyranosyl-22 $\alpha$-hydroxyhederagenin (2)

White amorphous powder; $[\alpha]_{\mathrm{D}}{ }^{25}+98.1^{\circ}(\mathrm{MeOH}, c$ 0.001); ${ }^{1} \mathrm{H}$ NMR (400 MHz, $\left.\mathrm{C}_{5} \mathrm{D}_{5} \mathrm{~N}\right)$ : Aglicon: $\delta 5.50(\mathrm{br}$ s, H-12), 4.55 (m, H-22), 4.30 (m, H-3), 4.26 (d, J $10 \mathrm{~Hz}$, H-23a), 3.91 (d, J $10 \mathrm{~Hz}, \mathrm{H}-23 \mathrm{~b}$ ), 3.38 (dd, $J 3.4 / 8.7 \mathrm{~Hz}$, H-12), 1.34 (s, 3H-27), 1.15 (s, 3H-24), 1.09 (s, 3H-30), 1.09 (s, 3H-26), 1.00 (s, 3H-25), 0.98 (s, 3H-29), Arabinose: 5.06 (d, J 7 Hz, H-1), 4.63 (m, H-2), 4.02 (dd, J 3.9/8.1 Hz, H-3), 4.13 (m, H-4), 4.33 (m, H-5a), 3.65 (br d, J 10.8 Hz, H-5b), Rhamnose: 6.31 (br s, H-1), 4.91 (m, H-2), 4.80 (dd, $J$ 2.9/9.5 Hz, H-3), 4.43 (t, $J 9.5$ Hz, H-4), 4.87 (dq, $J$ 6.2/9.5 Hz, H-5), 1.58 (d, J 6.2 Hz, 3H-6), Xylose: 5.29 (d, J7.3 Hz, H-1), 3.91 (t, J 8.8 Hz, H-2), 3.97 (t, J9.5 Hz, H-3), 4.01 (dt, $J 9.5 / 5.1 \mathrm{~Hz}, \mathrm{H}-4), 4.11$ (dd, $J 11.0 / 5.1 \mathrm{~Hz}$, H-5a), 3.55 (dd, $J$ 11.0/9.5 Hz, H-5b); ${ }^{13} \mathrm{C}$ NMR (100 MHz,
$\mathrm{C}_{5} \mathrm{D}_{5} \mathrm{~N}$ ):see Table 1; ESIMS (daughter ion scan, $35 \mathrm{eV}$.): 897 [M-H] $]^{-}$(100), 765 [M-H-Xyl]' (29), 747 [M-H-Xyl$\mathrm{OH}]^{-}$(8), 619 [M-H-Xyl-Rha]- (63), 601 [M-H-Xyl-Rha$\mathrm{OH}]^{-}(52), 487$ [22-Hydroxy-hederagenin - H] ${ }^{-}$(78).

\section{Acknowledgments}

The authors are gratefull to Fundação de Amparo à Pesquisa do Estado de São Paulo (FAPESP), Conselho Nacional de Desenvolvimento Científico e Tecnológico (CNPq), Coordenação de Aperfeiçoamento de Ensino Superior (CAPES) and Financiadora de Estudos e Projetos (FINEP) for financial support.

\section{References}

1. Voutquenne, L.; Ann Pharm Fr. 2001, 59, 407.

2. Murgu, M.; Rodrigues-Filho, E.; J. Braz. Chem. Soc. 2006, 17, 1281.

3. Gruiz, K.; Adv. in Exper. Med. Biol. 1996, 404, 527.

4. Morrissey, J. P.; Osbourn A. E.; App. Environ. Microbiol. 1999, 63, 708.

5. Bower, P.; Clarke, B. R.; Lunness, M. J.; Daniels, M. J.; Osbourn, A. E.; Science 1995, 267, 371.

6. Maor, R.; Shirasu, K.; Curr. Opin. Microbio. 2005, 8, 399.

7. Amaral, L. S.; Murgu, M.; Rodrigues-Filho, E.; Souza, A. Q. L.; Sarquis, M. I. M.; World J. Microbiol. Biotech. 2008, in press.

8. Grover, R. K.; Roy, A. D.; Roy, R.; Joshi, S. K.; Srivastava, V.; Arora, S. K.; Magn. Reson. Chem. 2005, 43, 1072.

9. Melek, F. R.; Miyase, T.; Ghaly, N. S.; Nabil, M.; Phytochemistry 2007, 68, 1261.

10. Romussi, G.; Falsone, G.; Arch. Pharm. (Weinheim) 1985, 318 , 219.

11. Yoshikawa, M.; Shimada, H.; Morikawa, T.; Yoshizumi, S.; Matsumura, N.; Murakami, T.; Matsuda, H.; Hori, K.; Yamahara, J.; Chem. Pharm. Bull. 1997, 45, 1300.

12. Shin, H. Y.; Park, S. Y.; Sung, J. H.; Kim, D. H.; App. Environ. Microbiol. 2003, 69, 7116.

13. Woods, K.; W., Hamilton; C. J., Field; R. A.; Carbohyd. Research 2004, 339, 2325.

14. Carter, J. P.; Spink, J.; Cannon, P. F.; Daniels, M. J.; Osbourn, A. E.; App. Environ. Microbiol. 1999, 65, 3364.

Received: August 23, 2007 Web Release Date: March 25, 2008

FAPESP helped in meeting the publication costs of this article. 


\section{Hydroxylation of a Hederagenin Derived Saponin by a Xylareaceous Fungus Found in Fruits of Sapindus saponaria}

Michael Murgu, ${ }^{a}$ Luiz F. Arruda Santos, ${ }^{a}$ Gezimar D. de Souza, ${ }^{a}$ Cristina Daolio, ${ }^{a}$ Bernd Schneider, ${ }^{b}$ Antônio Gilberto Ferreira ${ }^{a}$ and Edson Rodrigues-Filho*,a

${ }^{a}$ Departamento de Química, Universidade Federal de São Carlos, CP 676, 13565-905 São Carlos-SP, Brazil

${ }^{b}$ Max Planck Institute for Chemical Ecology, Beutenberg Campus, Hans-Knöll-Straße 8, D-07745 Jena, Germany

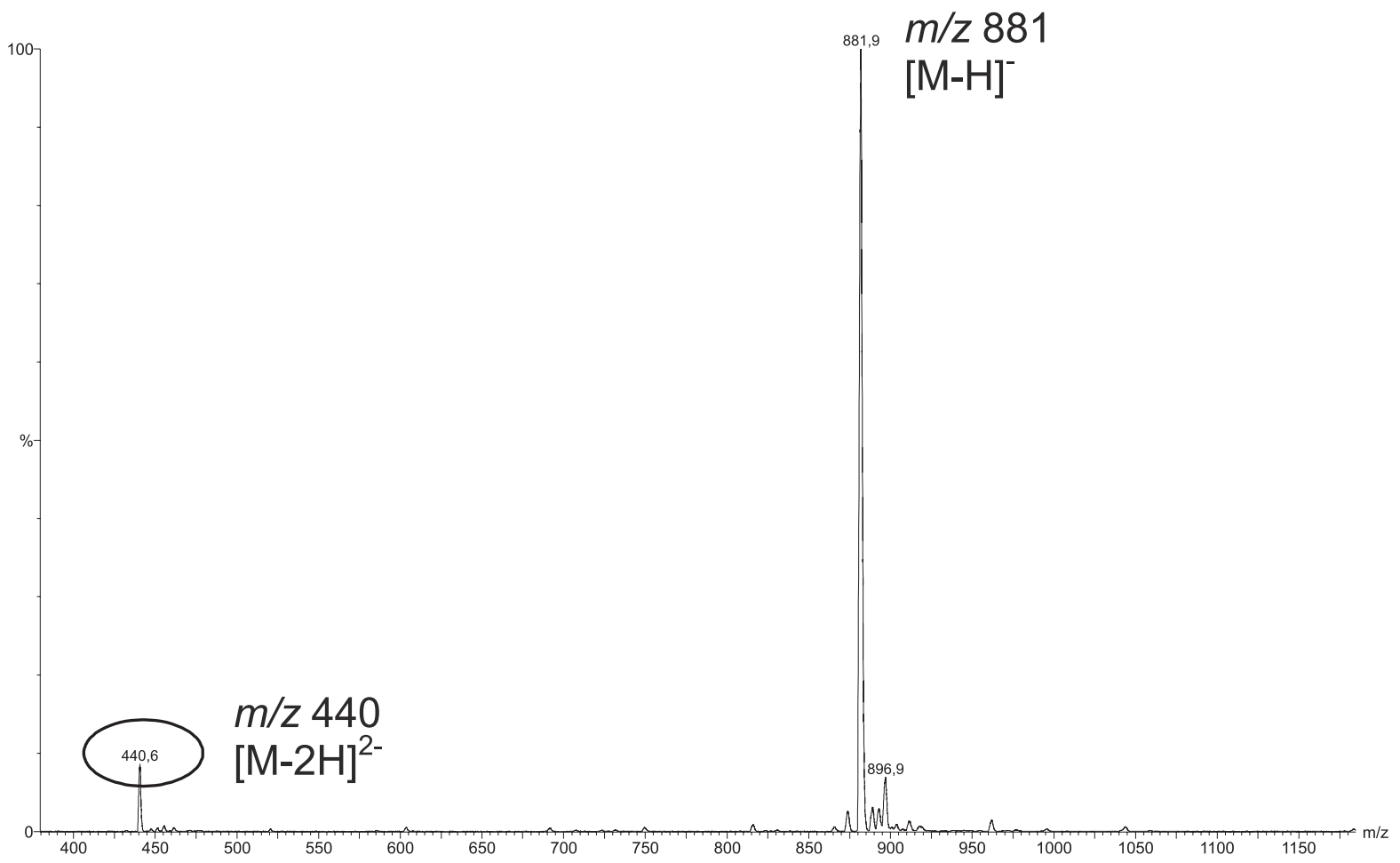

Figure S1. ESI-MS of saponin 1. 


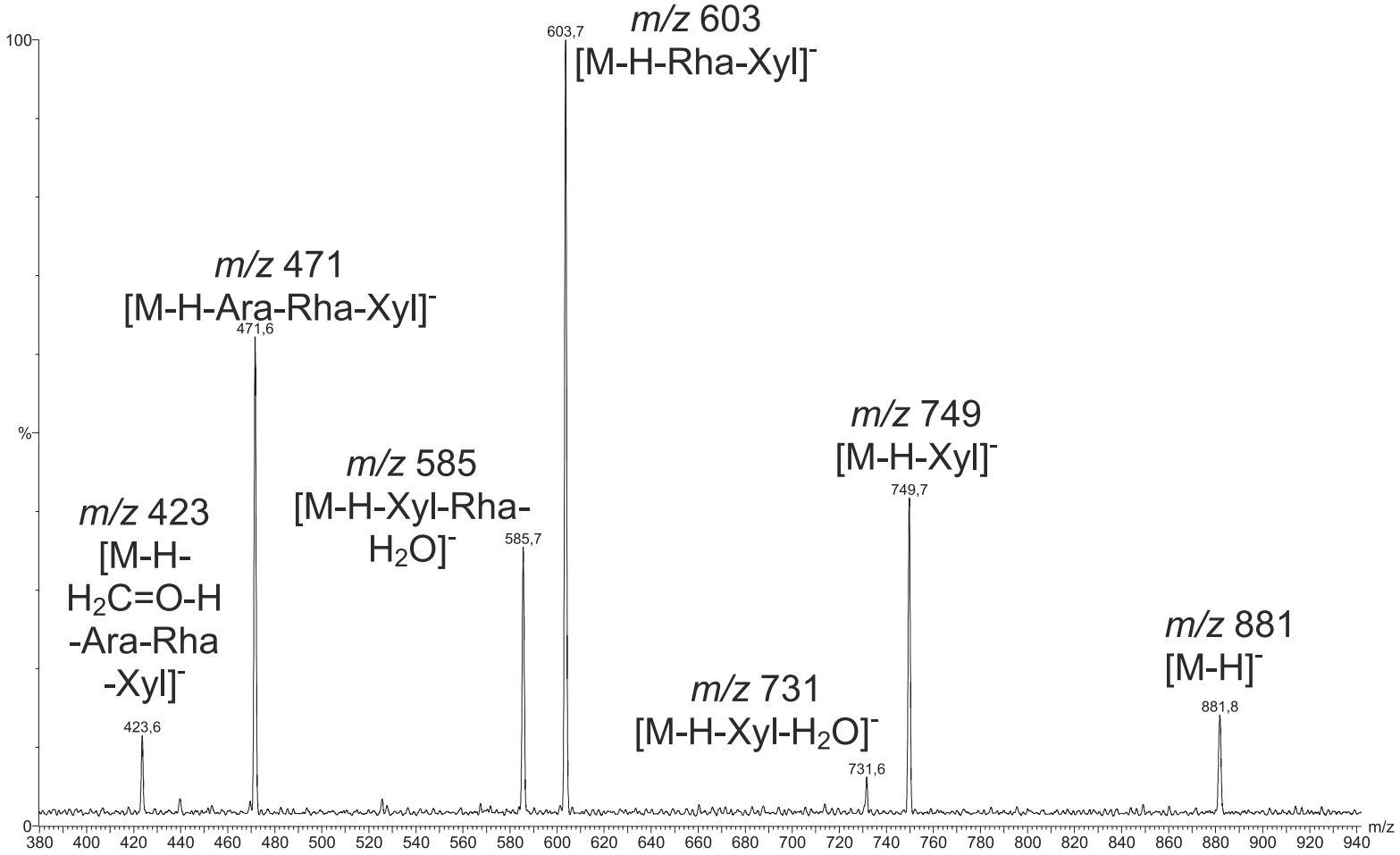

Figure S2. ESI-MS/MS of saponin 1.

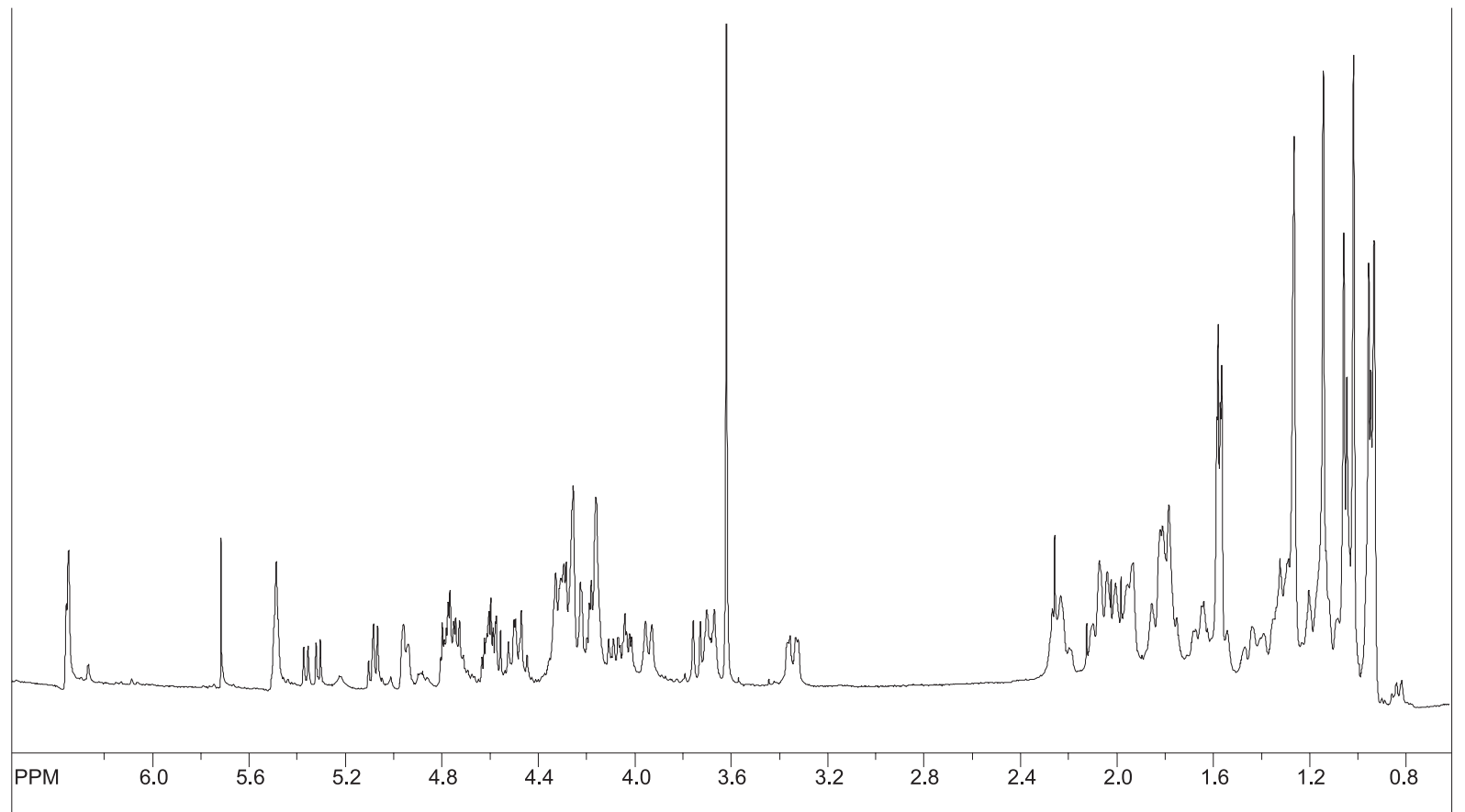

Figure S3. ${ }^{1} \mathrm{H}$ NMR spectrum (400 MHz, $\mathrm{C}_{5} \mathrm{D}_{5} \mathrm{~N}$;TMS) of saponin $\mathbf{1}$. 


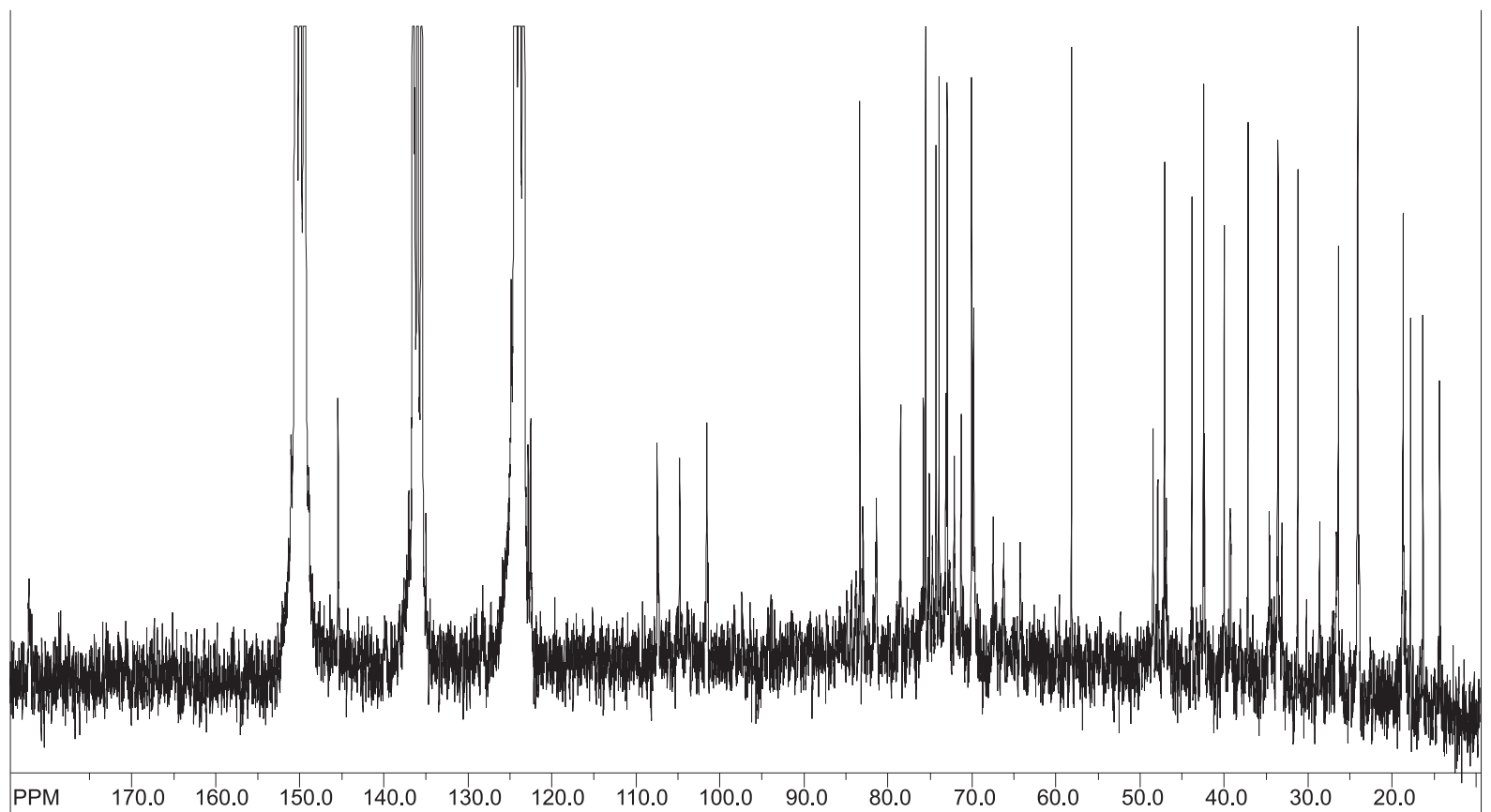

Figure S4. ${ }^{13} \mathrm{C}$ NMR spectrum $\left(100 \mathrm{MHz}, \mathrm{C}_{5} \mathrm{D}_{5} \mathrm{~N}\right.$; TMS $)$ of saponin $\mathbf{1}$.
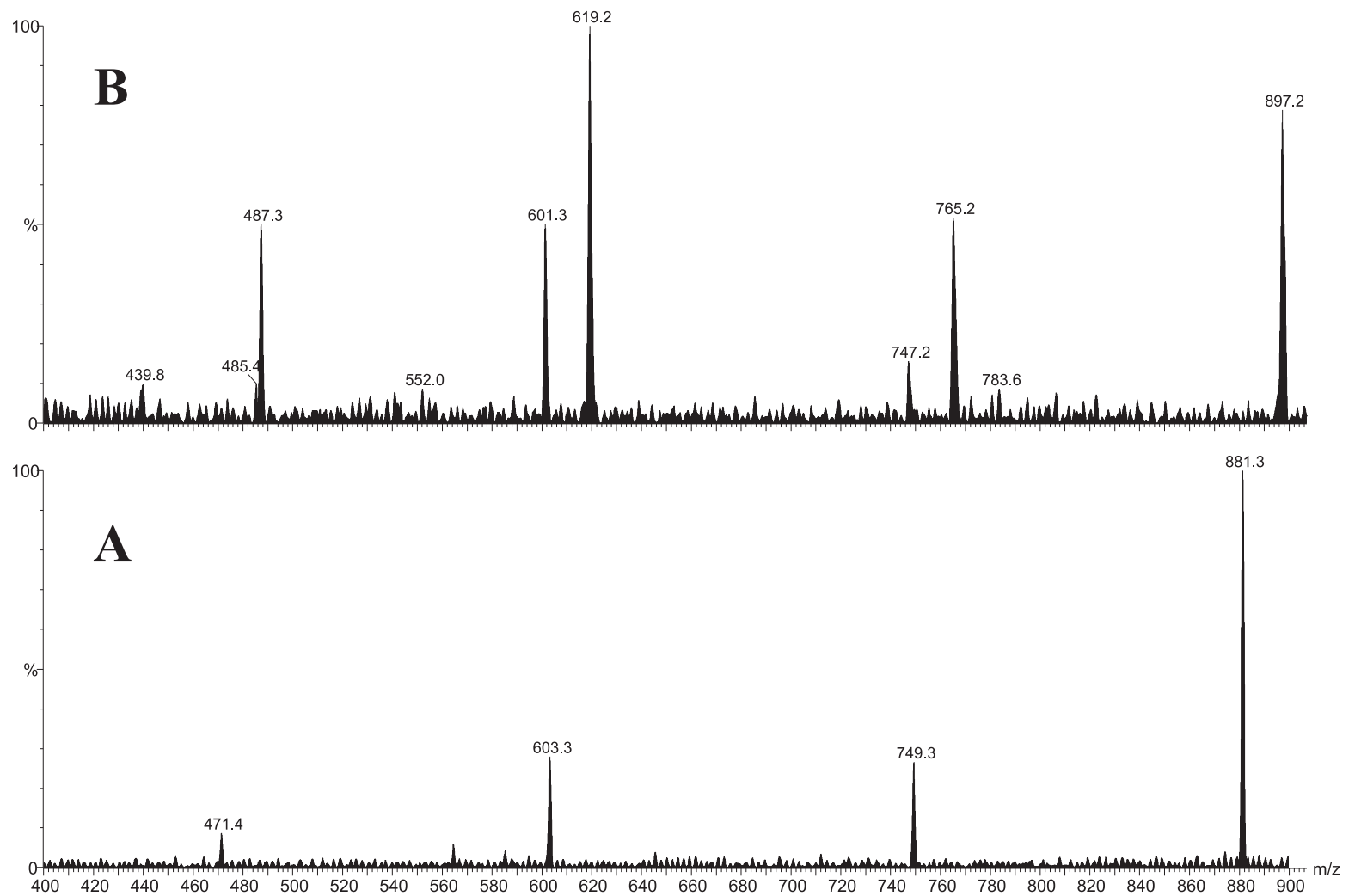

Figure S5. ESI-MS/MS of saponin 2 (A) and 1 (B). 


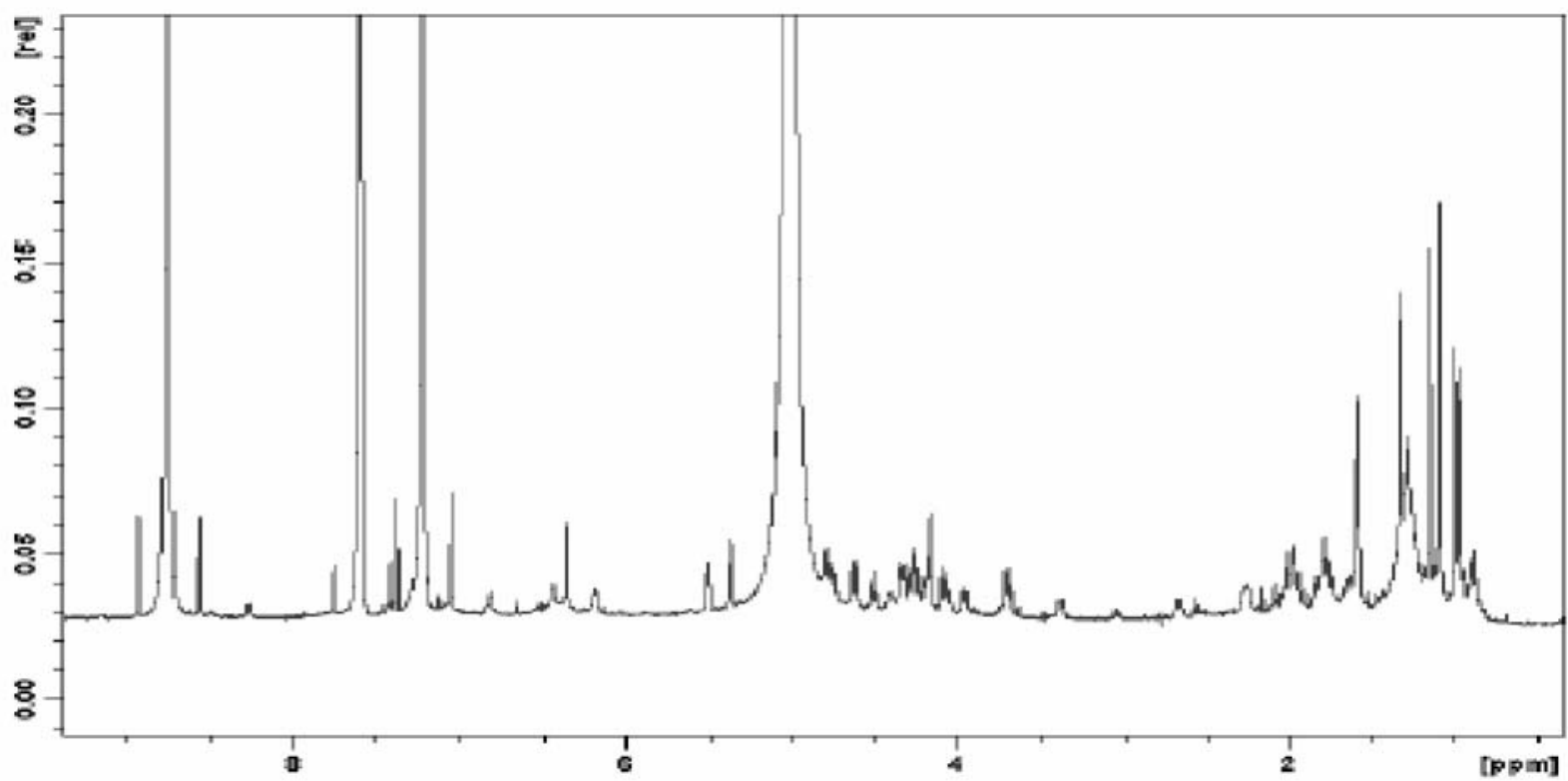

Figure S6. ${ }^{1} \mathrm{H}$ NMR spectrum $\left(500 \mathrm{MHz}, \mathrm{C}_{5} \mathrm{D}_{5} \mathrm{~N}\right.$; TMS) of saponin 2.

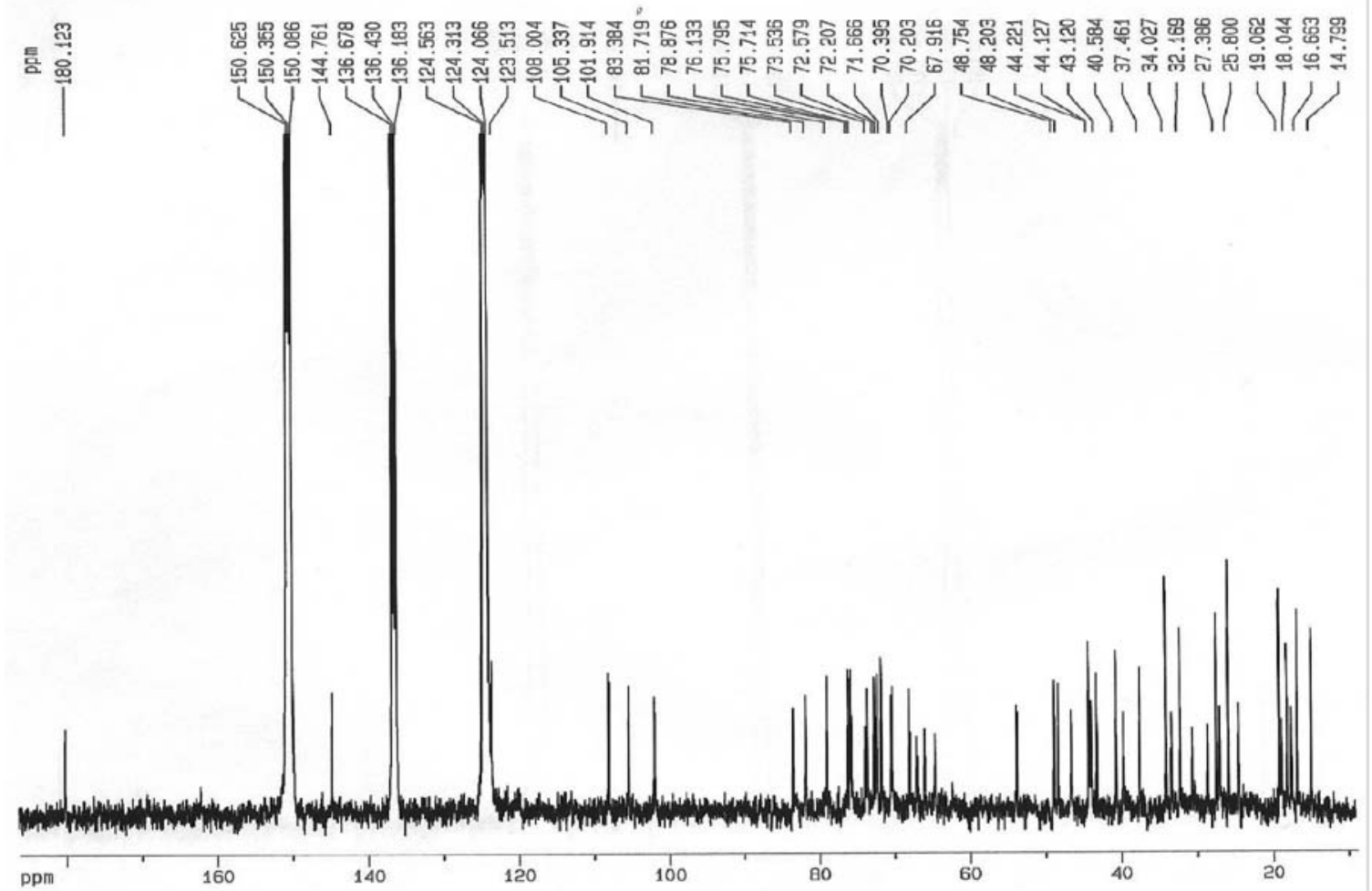

Figure S7. ${ }^{13} \mathrm{C}$ NMR spectrum (100 MHz, $\left.\mathrm{C}_{5} \mathrm{D}_{5} \mathrm{~N} ; \mathrm{TMS}\right)$ of saponin 2. 


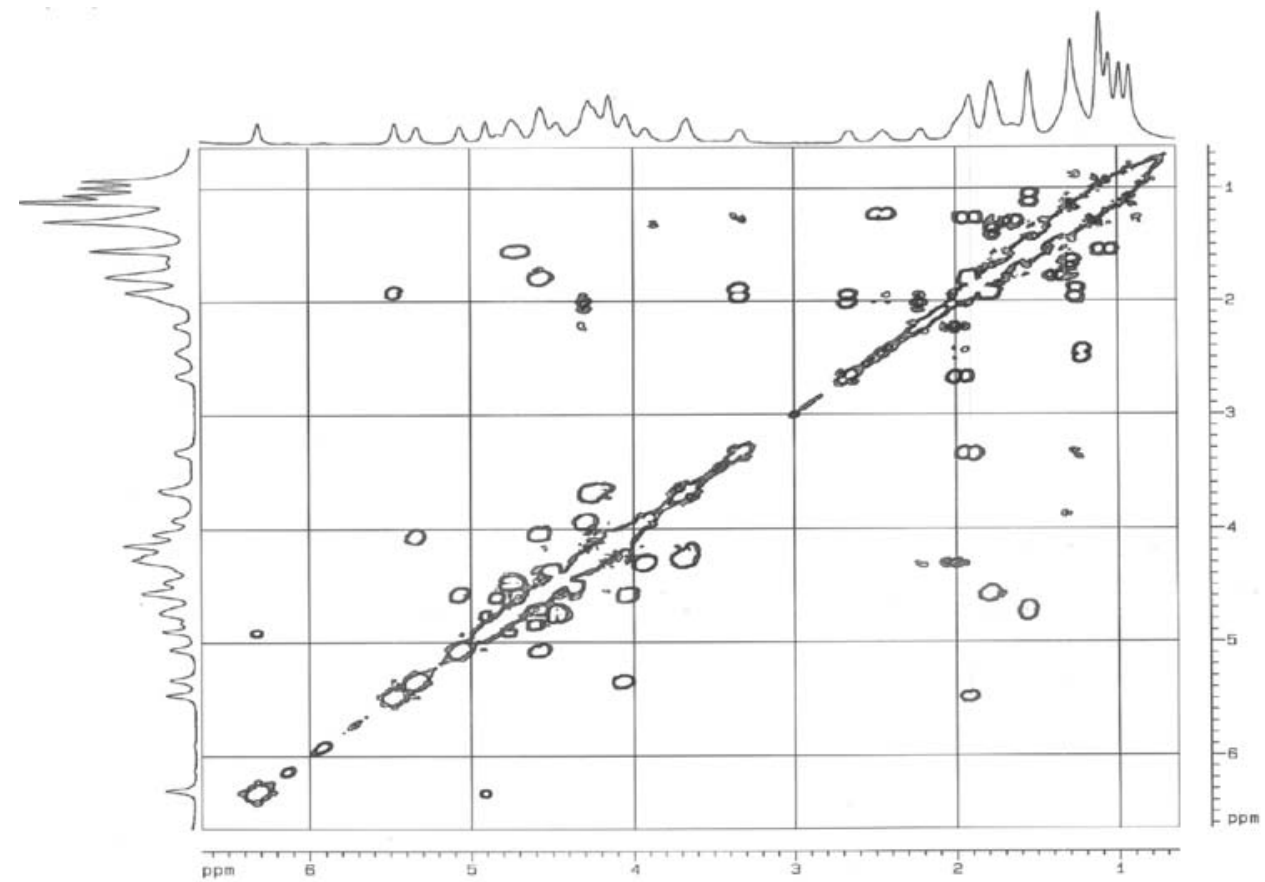

Figure S8. 2D ${ }^{1} \mathrm{H}-{ }^{1} \mathrm{H}$ COSY NMR spectrum (400 MHz, $\mathrm{C}_{5} \mathrm{D}_{5} \mathrm{~N}$;TMS) of saponin 2.

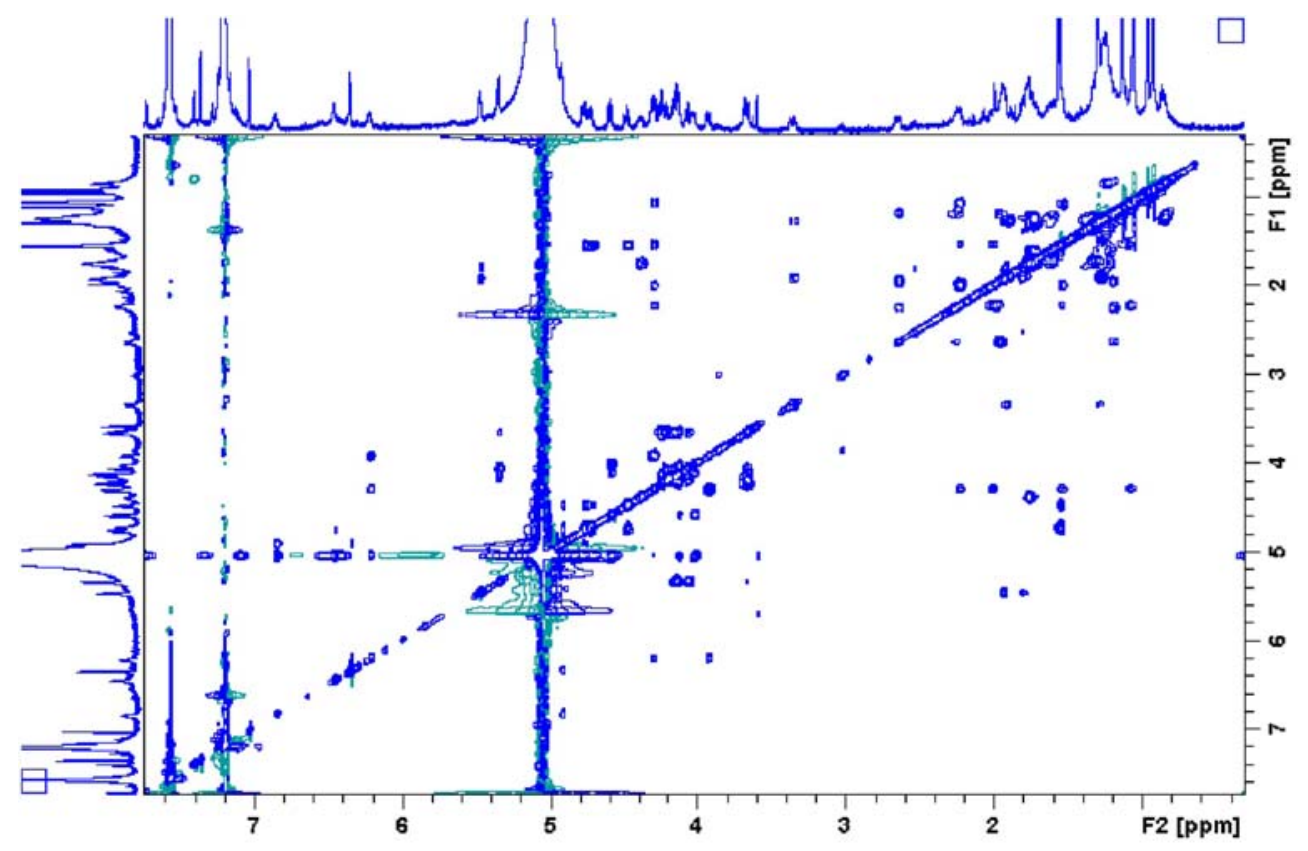

Figure S9. 2D ${ }^{1} \mathrm{H}-{ }^{1} \mathrm{H}$ TOCSY NMR spectrum (500 MHz, $\mathrm{C}_{5} \mathrm{D}_{5} \mathrm{~N}$;TMS) of saponin 2. 


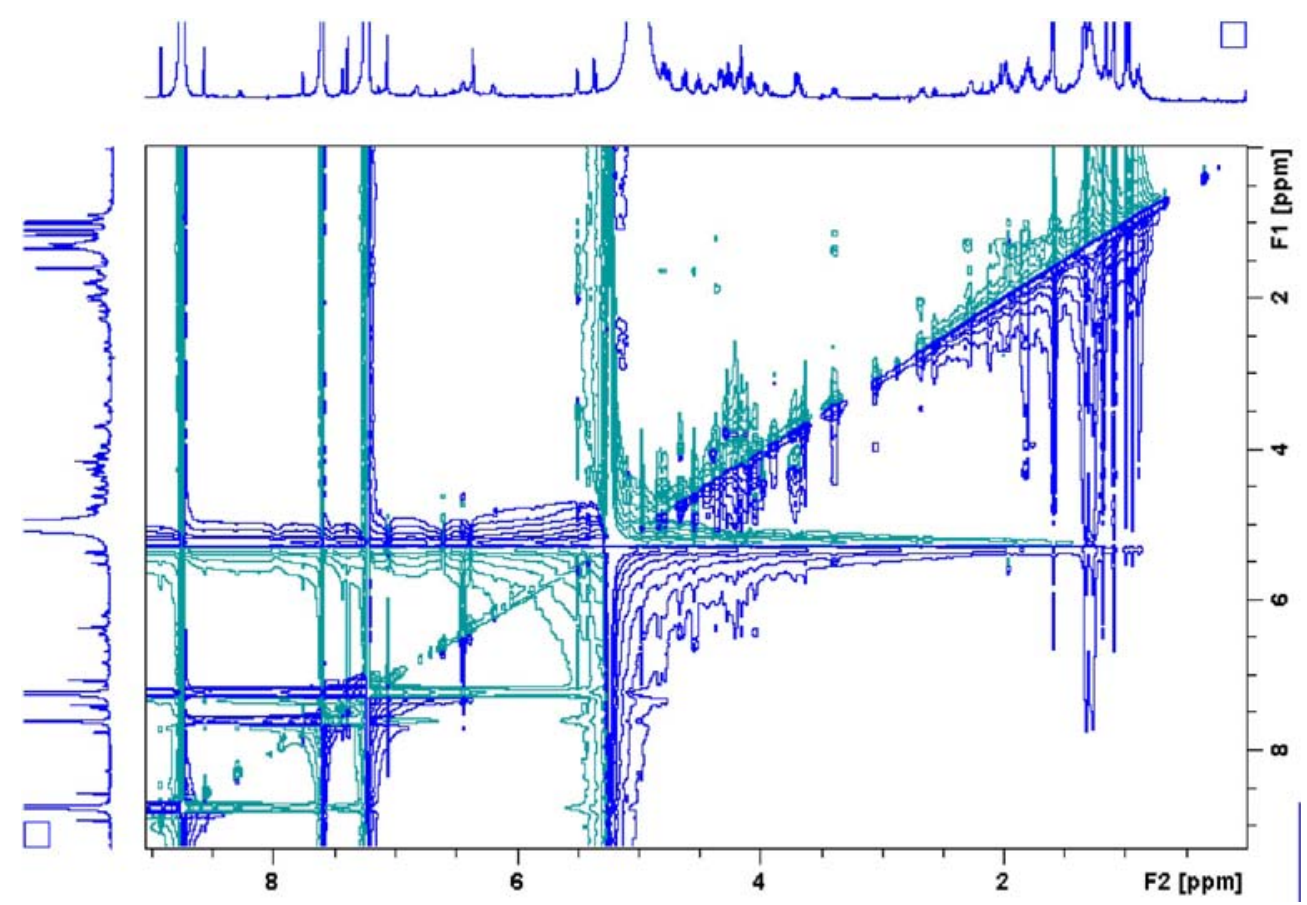

Figure S10. 2D ${ }^{1} \mathrm{H}-{ }^{1} \mathrm{H}$ ROESY NMR spectrum (500 MHz, $\mathrm{C}_{5} \mathrm{D}_{5} \mathrm{~N}$;TMS) of saponin 2.
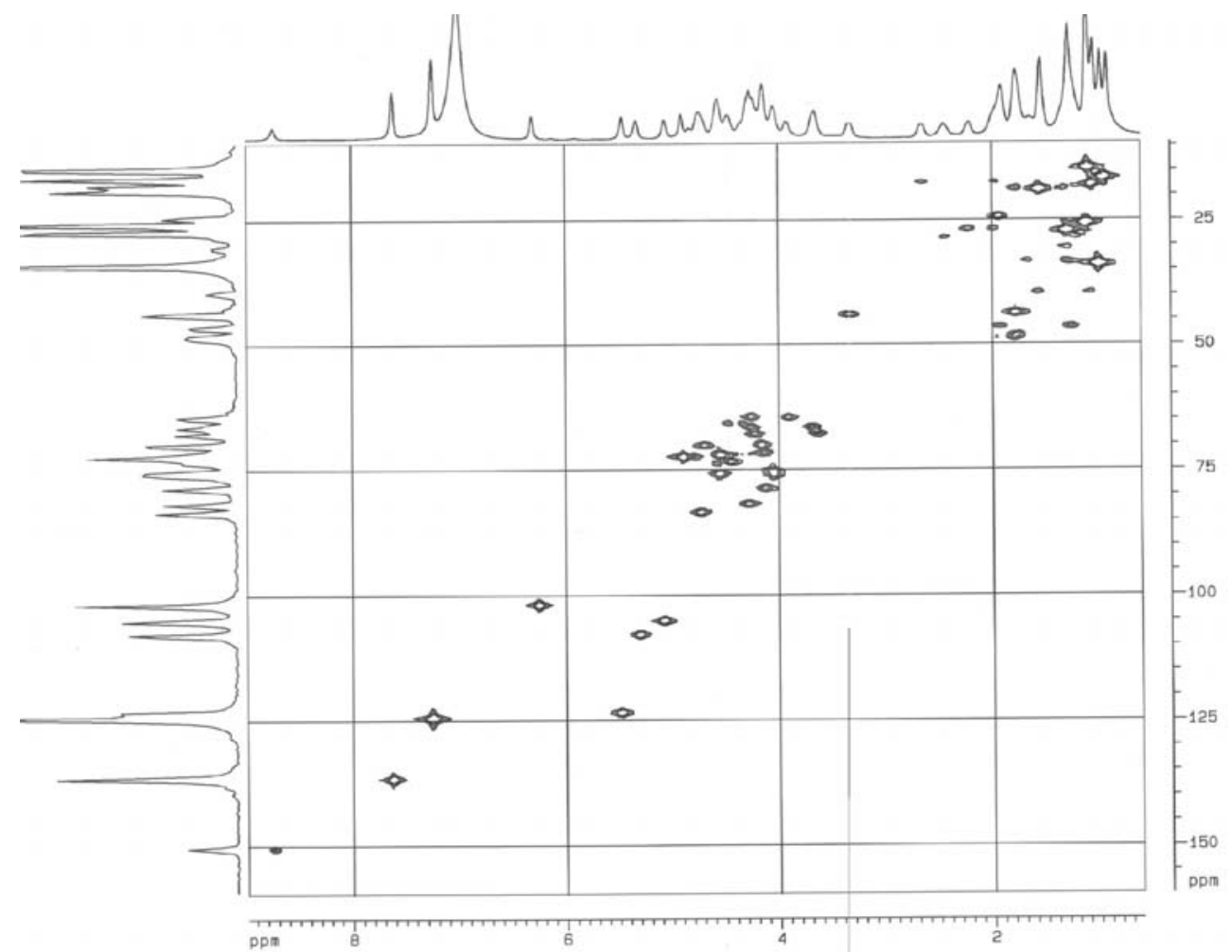

Figure S11. HSQC NMR experiment (400 MHz, $\mathrm{C}_{5} \mathrm{D}_{5} \mathrm{~N}$;TMS) of saponin 2. 


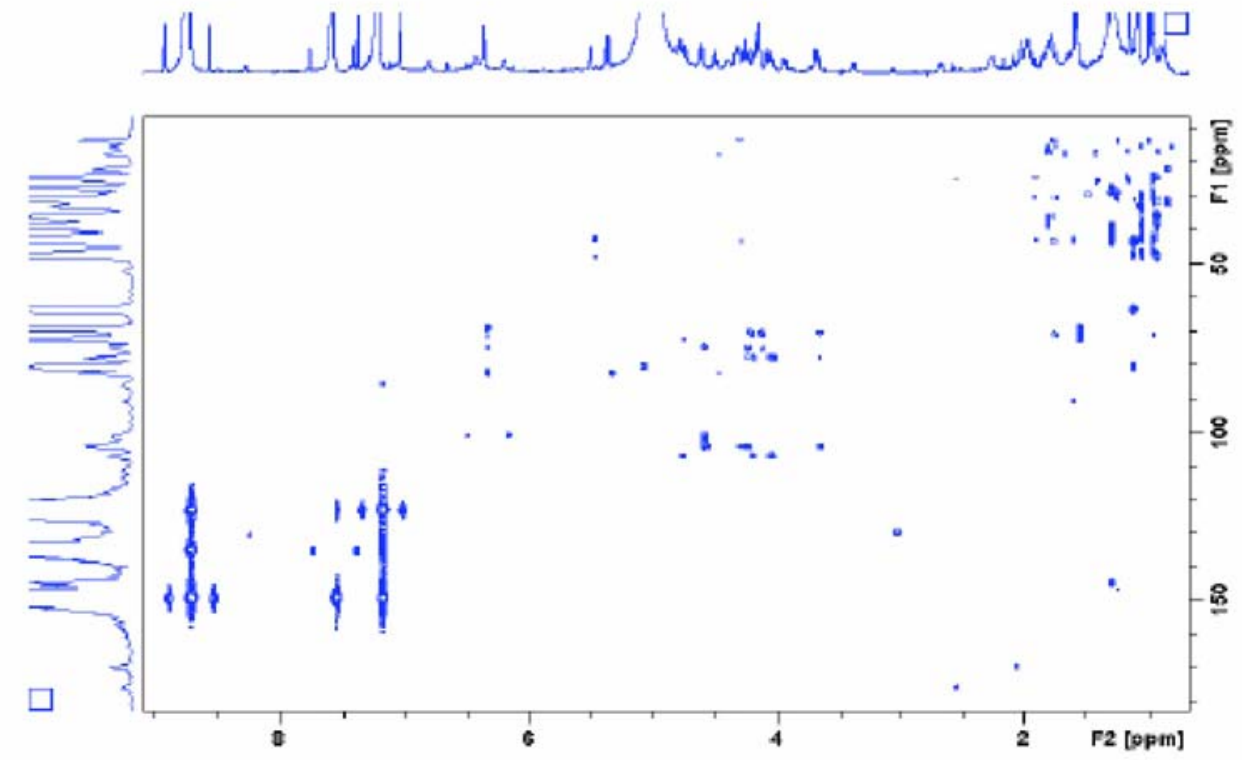

Figure S12. HMBC NMR experiment (500 MHz, $\mathrm{C}_{5} \mathrm{D}_{5} \mathrm{~N} ; \mathrm{TMS}$ ) of saponin 2. 